\title{
Estacas de diferentes diâmetros na propagação de Lippia alba (Mill.) N.E.Br. - Verbenaceae
}

MARCHESE, J.A.*; PISSAIA, E.; BOCCHESE, V.C.C.; CAMBRUZZI, E.; COLUSSI, G.; HART, V.; MAGIERO, E.C. Curso de Agronomia - Universidade Tecnológica Federal do Paraná, CEP: 85503-390, Pato Branco-Brasil *abramo@pq.cnpq.br

RESUMO: Este trabalho teve por objetivo avaliar o efeito de diferentes diâmetros de estacas na propagação de Lippia alba. Foram testadas estacas de $25 \mathrm{~cm}$ de comprimento, com diâmetros de 0,3-0,5 cm; 0,6-0,9 cm e 1-1,2 cm. Aos 30 e 60 dias após o plantio das estacas foram determinadas as características biométricas, como porcentagem de enraizamento, número de brotos, comprimento dos brotos, massas secas de brotos, estacas, raízes e total. Todos os diâmetros de estacas apresentaram altas taxas de enraizamento aos 30 dias, comprovando que a $L$. alba é uma espécie de fácil propagação por estaquia. A produção de mudas de $L$. alba deve ser realizada com estacas entre 1-1,2 cm de diâmetro, que foi superior aos outros diâmetros testados na maioria das características biométricas determinadas.

Palavras-chave: estaquia, planta medicinal, propagação vegetativa

ABSTRACT: Different diameters of cuttings on the propagation of Lippia alba (Mill.) N.E.Br. Verbenaceae. The aim of this work was to study the effect of different diameters of cuttings on the propagation and growth of Lippia alba. Cuttings of $25 \mathrm{~cm}$ length, with three different diameters: $0.3-0.5 \mathrm{~cm}, 0.6-0.9 \mathrm{~cm}$ and $1-1.2 \mathrm{~cm}$, were tested. At 30 and 60 days after the planting of cuttings, the following biometric parameters were determined rooting percentage; number of buds, length of buds; dry matter of buds, cuttings and roots; and total dry matter. All diameters of cuttings presented high rates of rooting after 30 days, confirming that $L$. alba is an easy-to-root species. $L$. alba seedling production should use cuttings between $1-1.2 \mathrm{~cm}$ diameter, which was better than the others diameters considering most of the tested parameters.

Key words: cuttings, medicinal plant, vegetative propagation

Lippia alba (Mill.) N.E.Br. é uma planta pertencente à família Verbenaceae, espécie originária da América, crescendo desde a América Central (México) e Caribe, até extremos da América do Sul (Argentina), sendo conhecida por diversos nomes populares, como erva-cidreira, erva-cidreira brasileira, alecrim do campo, alecrim selvagem, falsa-melissa, cidró, salva-do-brasil, cidreira-de-arbusto, cidreira brava, entre outros (Gupta, 1995; Martins et al., 1995; Silva Junior, 1998; Lorenzi \& Matos, 2002; Barbosa et al., 2006).

A planta é perene, arbusto ou subarbusto muito ramificado, medindo entre $1,5 \mathrm{~m}$ e $2,0 \mathrm{~m}$ de altura, apresentando ramos finos, esbranquiçados, arqueados e quebradiços. As flores são reunidas em inflorescências capituliformes de eixo curto, de cor azul a violeta (Gupta, 1995; Matos, 1998; Lorenzi \&
Matos, 2002; Biasi \& Costa, 2003). Com relação ao desenvolvimento, vegeta em solos arenosos e nas margens dos rios, açudes, lagos e lagoas, em regiões de clima tropical, subtropical e temperado (Corrêa Junior, 1994), em altitudes de até 1800 m (Gupta, 1995).

A planta é muito utilizada, tanto pelo sabor agradável, como pelas propriedades analgésica, calmante, sedativa e citostática (Gupta, 1995; Ming, 1998; Lorenzi \& Matos, 2002). Há três quimiotipos de $L$. alba identificados em função dos componentes majoritários do óleo essencial, sendo o quimiotipo I, com elevados teores de citral e mirceno; quimiotipo II, com elevados teores de citral e limoneno; e quimiotipo III, com altos teores de carvona e limoneno. Os quimiotipos I e II têm ação calmante e espasmolítica suaves, o II forte atividade sedativa e 
ansiolítica, e o III atividade mucolítica, isto é, facilita a expectoração. Os quimiotipos I e II, ricos em citral, são eficazes no alívio de cólicas intestinais e uterinas (Lorenzi \& Matos, 2002). Também, L. alba é frequentemente cultivada como ornamental em jardins (Gupta, 1995).

Esta espécie é encontrada em estado natural e cultivada no Paraná (Ming, 1998). O amplo emprego e relevância desta planta justificam a escolha como tema de estudos, sejam eles de interesse farmacológico ou agronômico.

De acordo com Paiva \& Gomes (2001), a propagação vegetativa é de grande importância quando se deseja multiplicar um genótipo que apresenta características que podem se perder quando propagadas por sementes. No caso das plantas medicinais, a propagação vegetativa é uma forma de impedir variações nos teores dos princípios ativos e de manter a qualidade do produto final (Montanari Júnior, 2002; Marchese \& Figueira, 2005). A estaquia é a técnica de maior viabilidade econômica (processo rápido e de baixo custo), dentre os métodos de propagação vegetativa (Silva, 1985; Paiva \& Gomes, 2001), e que permite a obtenção de grande número de mudas a partir de poucas plantasmatrizes (Lima et al., 2006).

Estudos sobre a propagação de espécies medicinais são de elevada importância, uma vez que servem de base para a domesticação e o sucesso do cultivo dessas plantas (Carvalho Júnior et al., 2009). Porém, escassas são as pesquisas sobre propagação dessas plantas, inclusive $L$. alba. No tocante aos aspectos agronômicos, muito pouco se tem a respeito desta planta; não existem pesquisas e literatura suficientes, havendo, pois, necessidade de se estabelecer técnicas apropriadas de produção desta espécie, com o intuito de se evitar a depredação e possibilitar a produção de matéria prima vegetal de boa qualidade e em moldes econômicos (Ming, 1998). Famílias de pequenos produtores rurais vêm encontrando no cultivo de espécies medicinais uma oportunidade ímpar de diversificar a propriedade e aumentar a renda, uma vez que a produção de "commodities" exige grandes áreas para um mínimo de rentabilidade (Ming et al., 2003).

Este trabalho teve por objetivo avaliar o efeito de diferentes diâmetros de estacas na propagação de Lippia alba.

O presente ensaio foi conduzido em estufa plástica, localizada nas dependências do Curso de Agronomia da UTFPR - Universidade Tecnológica Federal do Paraná, Campus Pato Branco, em Pato

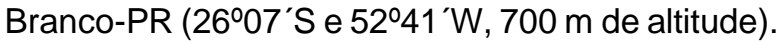

Foram coletados ramos sadios de $L$. alba do Horto de Plantas Medicinais e Aromáticas da UTFPR, em 08/08/2006, e em seguida foram confeccionadas estacas de $25 \mathrm{~cm}$ de comprimento, com três faixas de diâmetros, 0,3-0,5 cm; 0,6-0,9 $\mathrm{cm}$ e 1-1,2 cm, deixando-se três folhas inteiras em cada estaca. Exsicatas da espécie utilizada encontram-se incorporadas no Herbário "Irina Delanova de Gemtchjnicov" (BOTU) da Universidade Estadual Paulista, em Botucatu-SP, sob o número 24137. As estacas foram plantadas em bandejas de poliestireno expandido com 72 células contendo substrato comercial Turfa Férti ${ }^{\circledR}$, uma mistura de turfa, perlita, calcário e fertilizante mineral, cujas análises química e física são apresentadas na Tabela 1. Diariamente, as plantas foram irrigadas por aspersão recebendo uma quantidade de $12 \mathrm{~mm}$ de água. As médias das temperaturas máxima e mínima durante o experimento foram $30,12^{\circ} \mathrm{C}$ e $10,21^{\circ} \mathrm{C}$, respectivamente.

As avaliações foram realizadas aos 30 e 60 dias após o plantio das estacas, sendo determinadas as características biométricas: porcentagem de enraizamento, número de brotos, comprimento dos brotos, massas secas de brotos, estacas, raízes e total. Visando a obtenção das massas secas, o material vegetal foi embalado individualmente, em sacos de papel kraft e a secagem feita em estufa com circulação forçada de ar a $\pm 80^{\circ} \mathrm{C}$, até massa constante.

O delineamento experimental utilizado foi em blocos ao acaso, com três repetições para cada tratamento (10 estacas por repetição). Os resultados das avaliações foram submetidos à análise de variância e as médias comparadas pelo teste Tukey a $5 \%$ de probabilidade.

Nas avaliações realizadas aos 30 dias, os maiores valores para massa seca de brotos (Figura 1A) e massa seca de raiz (Figura 1B), bem como o maior comprimento de brotos (Figura 1E) e o maior número de brotações (Figura 1F), foram obtidos na

TABELA 1. Resultado da análise física e química do substrato comercial Turfa Fértil ${ }^{\circledR 1}$. UTFPR, 2010.

\begin{tabular}{ccccccccccc}
\hline $\begin{array}{c}{ }^{1} \mathbf{C E} \\
\left(\mathrm{mS} \mathrm{cm}^{-1}\right)\end{array}$ & $\begin{array}{c}{ }^{1} \mathbf{D B S} \\
\left(\mathrm{Kg} \mathrm{m}^{-3}\right)\end{array}$ & $\begin{array}{c}{ }^{1} \mathbf{C R A} \\
(\%)\end{array}$ & $\begin{array}{c}{ }^{2} \mathbf{p H} \\
\mathrm{CaCl}_{2}\end{array}$ & $\begin{array}{c}{ }^{2} \mathbf{M O} \\
\mathrm{g} \mathrm{dm}^{-3}\end{array}$ & ${ }^{2} \mathbf{A l}^{+3}$ & ${ }^{2} \mathbf{C a}$ & ${ }^{2} \mathbf{M g}$ & ${ }^{2} \mathbf{K}$ & ${ }^{2} \mathbf{P}$ & ${ }^{2} \mathbf{V}$ \\
\hline $0,7 \pm 0,2$ & 330 & 64 & 4,2 & 66,0 & 1,4 & 1,4 & 1,1 & 0,2 & 1,5 & 16,7 \\
\hline
\end{tabular}

${ }^{1}$ Análise informada pelo fabricante do substrato na embalagem. ${ }^{2}$ Análise realizada no Laboratório de Solos da Universidade Tecnológica Federal do Paraná, Campus Pato Branco, Pato Branco-PR. CE = Condutividade elétrica; DBS = Densidade em base seca; CRA = Capacidade de retenção de água.

Rev. Bras. PI. Med., Botucatu, v.12, n.4, p.506-509, 2010. 
utilização de estacas de diâmetro entre 1-1,2 cm. Este foi o maior diâmetro utilizado no experimento e, possivelmente, devido à maior quantidade de reservas pré-existentes nestas estacas, ocorreu maior crescimento e desenvolvimento destas. Carboidratos de reserva servem como fonte de energia e produção de esqueletos carbônicos necessários para a produção de novos tecidos. Isso significa que sem um nível mínimo de carboidratos, o crescimento e desenvolvimento irão cessar. Portanto, baixa quantidade de reservas, como por exemplo, carboidratos, não fornecerá a energia necessária para que ocorra bom enraizamento das estacas (Veierskov, 1988; Mayer et al., 2006), pois a capacidade de uma estaca emitir raízes é função da interação de fatores endógenos e das condições ambientais proporcionadas ao enraizamento (Nicoloso et al., 2001). Resultados similares, foram encontrados por Biasi \& Costa (2003) em estudo com plantas de $L$. alba e também por Nicoloso et al. (2001) em plantas de Pfaffia glomerata,
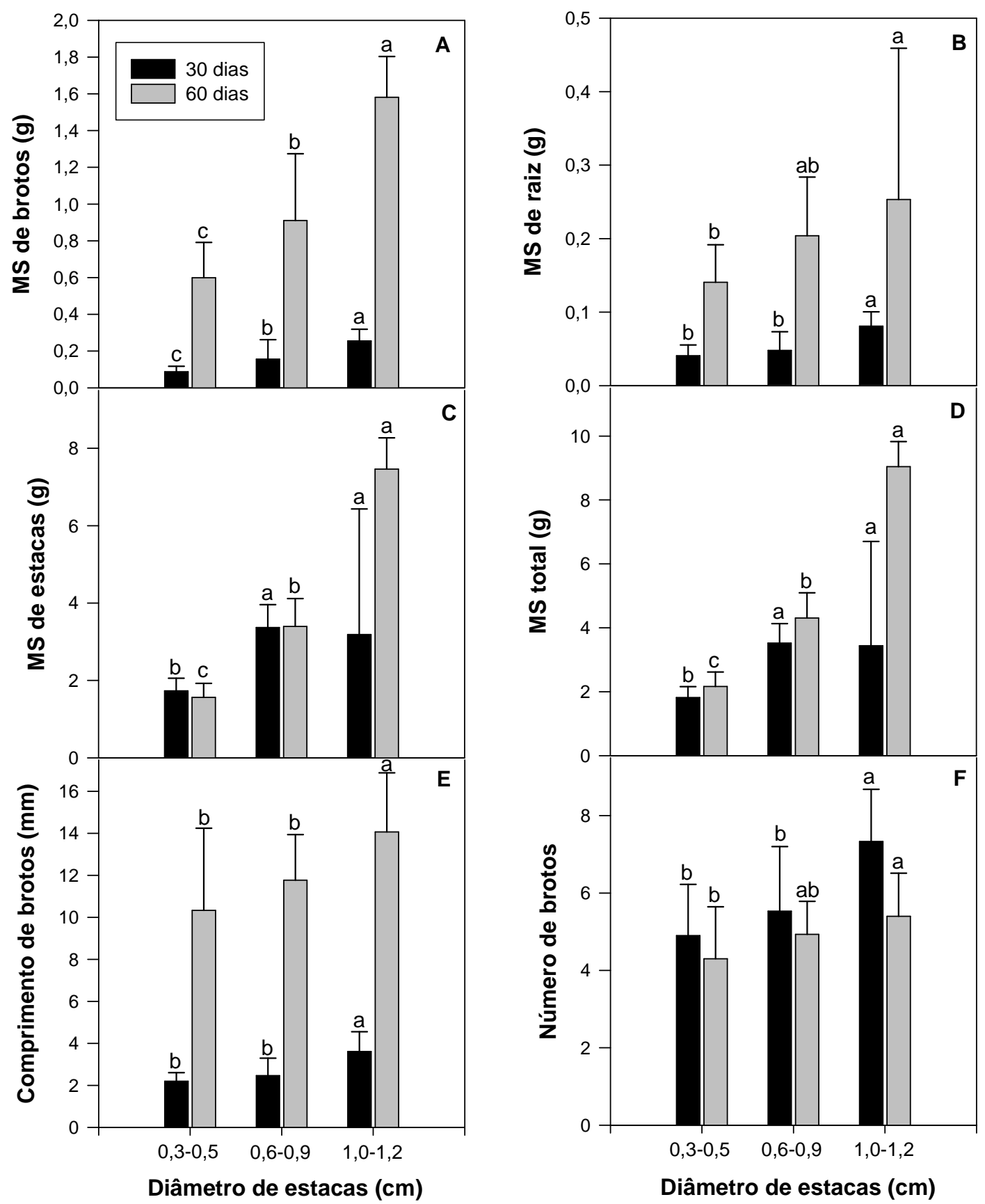

FIGURA 1. Efeito dos diâmetros de estaca: $0,3-0,5 \mathrm{~cm} ; 0,6-0,9 \mathrm{~cm}$ e 1-1,2 cm nas características biométricas: massa seca de brotos (A), massa seca de raízes (B), massa seca de estacas (C) e massa seca total (D), comprimento de brotos (E) e número de brotos $(F)$ em Lippia alba. Médias seguidas da mesma letra nas colunas de mesma cor, não diferem significativamente pelo teste Tukey a 5\% de probabilidade de erro. UTFPR, 2010. 
sendo que as estacas de maior comprimento e portanto, com maiores quantidades de reservas préexistentes, proporcionaram maior produção de biomassa em parte aérea e porção radicular. Ming (1998) reporta que estacas menos lignificadas e menores de 0,5 cm apresentam menor índice de pegamento no processo de estaquia. Contrariamente, Castro et al. (2002) sugerem a propagação vegetativa desta espécie através de hastes com diâmetro médio de $0,5 \mathrm{~cm}$. Para as características massa seca de estaca (Figura 1C) e massa seca total (Figura 1D) não houve diferença significativa entre os diâmetros $1-1,2 \mathrm{~cm}$ e $0,6-0,9 \mathrm{~cm}$.

$\mathrm{Na}$ avaliação realizada aos 60 dias, 0 diâmetro entre $1-1,2 \mathrm{~cm}$ foi superior aos outros tratamentos para massa seca de brotos (Figura 1A), massa seca de estaca (Figura 1C), massa seca total (Figura 1D) e comprimento de brotos (Figura 1E). Não houve diferença significativa entre o diâmetro 1-1,2 $\mathrm{cm}$ e 0,6-0,9 cm para número de brotos (Figura 1F) e massa seca de raiz (Figura 1B).

Os diâmetros de estaca testados não apresentaram diferença quanto ao percentual de enraizamento, que foi de $100 \%$ para todos os tratamentos, demonstrando grande facilidade de formação de raízes em estacas de $L$. alba, confirmando os resultados obtidos por Albuquerque et al. (2001); Rocha et al. (2001) e Biasi \& Costa (2003).

Nas condições deste trabalho, conclui-se que a produção de mudas de $L$. alba deve ser realizada com estacas entre $1-1,2 \mathrm{~cm}$ de diâmetro e que a estaquia mostrou ser eficiente como alternativa para a produção de mudas desta espécie, apresentando facilidade de enraizamento e desenvolvimento das estacas.

\section{REFERÊNCIA}

ALBUQUERQUE, H.A. et al. Estaquia de erva-cidreira quimiotipo II (citral-limoneno). Horticultura Brasileira, v.19, supl. CD-ROM, 2001.

BARBOSA, F.F. et al. Influência da temperatura do ar de secagem sobre o teor e a composição química do óleo essencial de Lippia alba (Mill.) N. E. BROWN. Química Nova, v.29, n.6, p.1221-5, 2006.

BIASI, L.A.; COSTA, G. Propagação vegetativa de Lippia alba. Ciência Rural, v.33, n.3, p.455-9, 2003.

CARVALHO JÚNIOR, W.G.O.; MELO, M.T.P.; MARTINS, E.R. Comprimento da estaca no desenvolvimento de mudas de alecrim-pimenta. Ciência Rural, v.39, n.7, p.2199-202, 2009.

CASTRO, D.M.; MING, L.C.; MARQUES, M.O.M. Biomass production and chemical composition of Lippia alba (Mill.) N.E.Br. ex Britt \& Wilson in leaves on different plant in different seasons. Acta Horticulturae, v.569, p.111-5, 2002.
CORRÊA JÚNIOR, C.; MING, L.C.; SCHEFFER, M. Cultivo de plantas medicinais, condimentares e aromáticas. 2.ed. Jaboticabal: FUNEP, 1994. 151p.

GUPTA, M. 270 Plantas medicinales Iberoamericanas.

Santafe de Bogotá: Presencia, 1995. 617p.

LORENZI, H.; MATOS, F.J.A. Plantas medicinais no

Brasil: nativas e exóticas. Campinas: Instituto Plantarum, 2002. 511p.

LIMA, R.L.S. et al. Comprimento de estacas e parte do ramo na formação de mudas de aceroleira. Revista Brasileira de Fruticultura, v.28, n.1, p.83-6, 2006. MARCHESE, J.A.; FIGUEIRA, G.M. O uso de tecnologias pré e pós-colheita e boas práticas agrícolas na produção de plantas medicinais e aromáticas. Revista Brasileira de Plantas Medicinais, v.7, n.3, p.86-96, 2005.

MARTINS, E.R. et al. Plantas medicinais. Viçosa: UFV, 1995. 220p.

MATOS, F.J.A. Farmácias vivas: sistema de utilização de plantas medicinais projetados para pequenas comunidades. 3.ed. Fortaleza: EUFC, 1998. 220p.

MAYER, J.L.S.; BIASI, L.A.; BONA, C. Capacidade de enraizamento de estacas de quatro cultivares de Vitis $L$. (Vitaceae) relacionada com os aspectos anatômicos. Acta Botanica Brasilica, v.20, n.3, p.563-8, 2006.

MING, L.C. Adubação orgânica no cultivo de Lippia alba (Mill.) N.E.Br. - VERBENACEAE. In: MING, L.C. et al. Plantas medicinais, aromáticas e condimentares: avanços na pesquisa agronômica. Botucatu: UNESP, 1998. v.2, p.165-91.

MING, L.C. et al. Manejo e cultivo de plantas medicinais: agumas reflexões sobre as perspectivas e necessidades no Brasil. In: COELHO, M.F.B.; COSTA JÚNIOR, P.; DOMBROSKI, J.L.D. Diversos olhares em etnobiologia, etnoecologia e plantas medicinais: anais do I Seminário Mato-grossense de Etnobiologia e Etnoecologia e II Seminário Centro-Oeste de Plantas Medicinais. Cuiabá: UNICEN, 2003. p.149-56.

MONTANARI JÚNIOR, I. Aspectos da produção comercial de plantas medicinais nativas. Campinas: CPQBA-UNICAMP, 2002. 7p. Disponível em: <http:// www.cpqba. unicamp.br/plmed/artigos/producao.htm>. Acesso em: 04 abr. 2008.

NICOLOSO, F.T.; CASSOL, L.F.; FORTUNATO, R.P. Comprimento da estaca de ramo no enraizamento de ginseng brasileiro (Pfaffia glomerata). Ciência Rural, v.31, n.1, p.57-60, 2001.

PAIVA, H.N.; GOMES, J.M. Propagação vegetativa de espécies florestais. Viçosa: UFV, 2001. 46p.

ROCHA, M.F.A. et al. Enraizamento de estacas de erva cidreira quimiotipo I (mirceno-citral). Horticultura Brasileira, v.19, supl., CD-ROM, 2001.

SILVA JUNIOR, A.A. Plantas medicinais. Itajaí: EPAGRI, 1998. CD-Rom.

SILVA, I.C. Propagação vegetativa: aspectos morfofisiológicos. Belém: CEPLAC. 1985. v.4, p.1-26.

VEIERSKOV, B. Relations between carbohydrates and adventitious root formation. In: DAVIS, T.D.; HAISSIG, B.E.; SANKHLA, N. Adventitious root formation in cuttings. Portland: Dioscorides, 1988. p.248-73. 